\title{
Secondary anterior crocodile shagreen of Vogt
}

\author{
R. G. TRIPATHI AND A. J. BRON \\ From the Department of Pathology, Institute of Ophthalmology, University of London, and the \\ Nuffield Laboratory of Ophthalmology, Oxford
}

Vogt (1930) described a bilateral central opacification of the cornea at the level of Bowman's layer comprising a mosaic of polygonal grey opacities separated by clear tissue. The changes occurred in an 8o-year-old man and were regarded as degenerative; Vogt termed this manifestation "crocodile shagreen of Bowman's membrane". A peripheral variety of the condition is commonly seen as a senile change (Bron, 1968). The axial form has been reported in youth in a man whose father had band-shaped keratopathy (Valerio, 1939, 1942) and has also been described as a dominantly inherited disorder (Kopša and Marušić, 1958). Secondary forms have been described after trauma (Müller, 1949; Franceschetti and Forni, 1950), associated with megalocornea (Boles-Carenini, I96I; Malbrán, D’Alessandro, and Valenzuela, 1965), and associated with iris malformation and band-shaped keratopathy (Collier, 1962).

The morbid anatomical basis for crocodile shagreen is uncertain. Bron and Tripathi (1969, 1970) have suggested that the anatomical structures responsible for the manifestation of the anterior corneal mosaic determine the polygonal organization of the mosaic degeneration. Moro and Amidei (1953) demonstrated a granular stippling of Bowman's layer similar to that seen in band-shaped keratopathy, and Müller (1949) reported in a posttraumatic case, an intermittent depression of Bowman's layer towards the stroma with rupture of this layer in the valleys so formed.

The present report describes a case of secondary anterior crocodile shagreen occurring in a blind degenerate globe. The histo-pathological findings and their significance are discussed.

\section{Case report}

A 73-year-old woman came to the Casualty Department of Moorfields Eye Hospital complaining of a red, painful right eye of 2 weeks' duration. The eye had been blind since the age of 15 when the patient suffered an episode of inflammation said to be due to infection.

There was no perception of light in the right eye and the vision in the left eye was $6 / 18$ improving to $6 / 12$ with

Address for reprints: R. C. Tripathi, M.S., Ph.D., Institute of Ophthalmology, Judd Street, London, WC1H 9QS a pin-hole. The right cornea was diffusely opaque and ulcerated centrally. Around the ulcerated zone the central portion of the superficial cornea showed a dense white reticular opacity within the confines of which were polygonal zones of a fainter opacification. The changes suggested a mosaic degeneration of the cornea (Fig. I). The anterior chamber was observed to be flat and although no leakage of aqueous was observed initially, frank perforation and prolapse of the iris occurred within a few days.

The left eye was normal in appearance apart from a minor peripheral corneal opacity; no sign of mosaic degeneration was present.

The right eye, being blind, irritable, and phthisical, was eventually enucleated August II, I97I. The cornea was trephined and fixed for histological study.

\section{HISTOPATHOLOGY}

Special attention was paid to the portion of the cornea corresponding to the mosaic degeneration seen clinically. The most prominent changes were found in the superficial cornea. Bowman's layer was thrown into prominent ridges variably spaced from I00 to $400 \mu \mathrm{m}$ apart (Fig. $2 a, b$ ). The epithelium accommodated itself to these ridges, and over the apices the epithelial cells were compressed and flattened, so that only minor surface irregularity was present (Fig. 2a,b). Bowman's layer was somewhat variable in thickness and ruptured in a few places. A granular deposit was present irregularly in Bowman's layer; it heavily encrusted the peak of each fold and often the entire ridge (and occasionally the connective tissue beneath), but was spread only sparsely in the valleys, usually confined to the subepithelial surface of Bowman's layer (Fig. 2b). Histochemically the deposit stained black with von Kossa, deep purple with quinalizarine, bright blue with Alcian blue, blue with colloidal iron, and orange red with alizarine, and showed a negative reaction with periodic acid-Schiff. These staining characteristics indicated the presence of calcium. The separation of the ridges seen by light microscopy corresponded to those of the reticular pattern seen on biomicroscopy. The stroma as a whole was thinned and scarred, and anteriorly followed the undulating contour of Bowman's layer and showed superficial vascularization peripherally. 


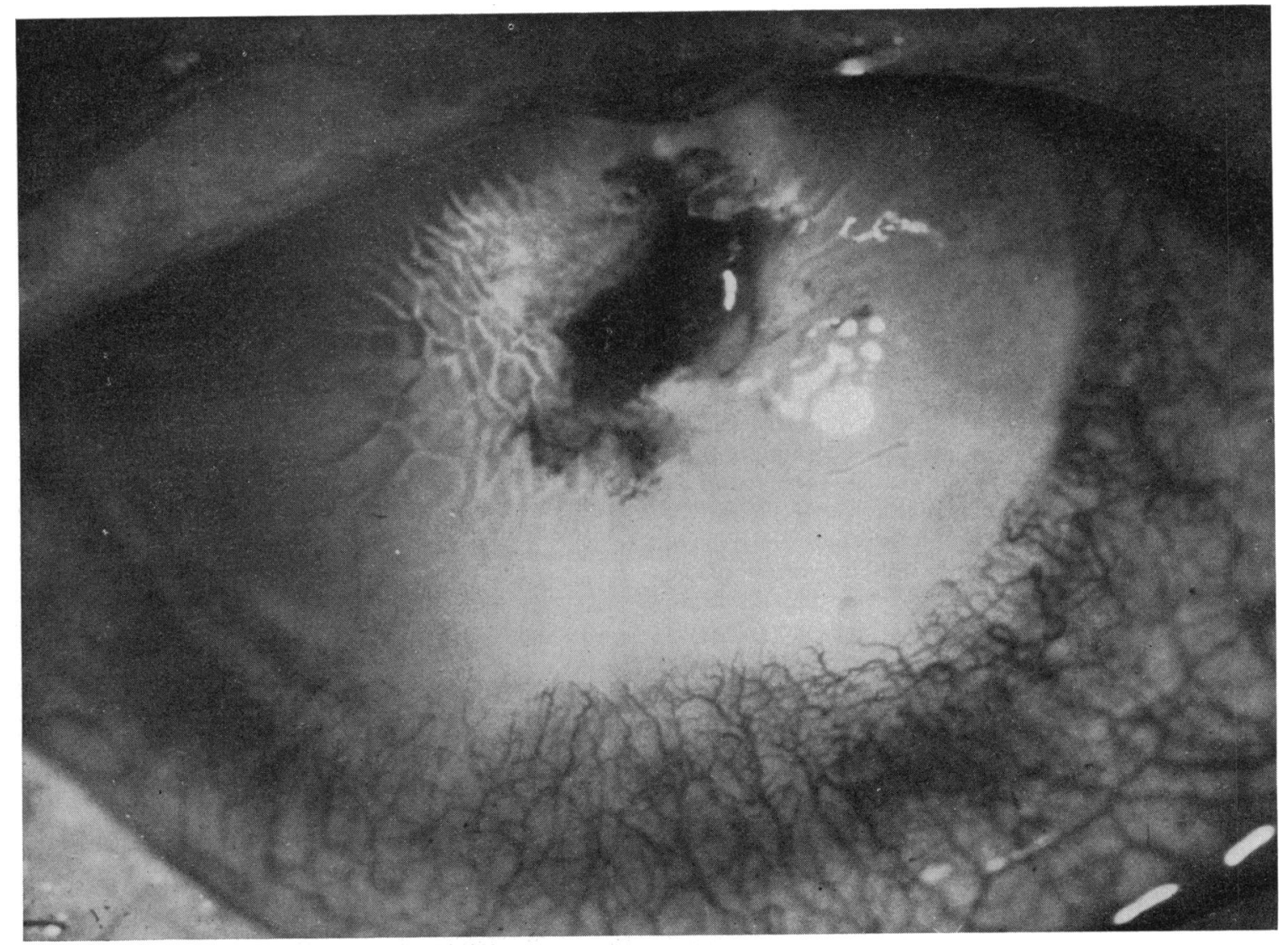

FIG. I Mosaic pattern on corneal surface seen clinically.

Descemet's membrane was of irregular thickness and the endothelium was degenerate and in places absent. The central cornea was perforated. Sections of the remainder of the eye showed anterior peripheral synechiae occluding the angle of the anterior chamber. The iris and ciliary body were atrophic and infiltrated by inflammatory cells. The choroid showed marked atrophic changes and some thickening of Bruch's membrane with drusen formation. The retina was totally detached and showed areas of haemorrhage, atrophy, cystoid degeneration, and gliosis. Retinitis proliferans was present in association with vitreous haemorrhage. The lens was calcified, cataractous, disorganized, and dislocated. The optic nerve was gliosed.

\section{Discussion}

It appears from our present study and those of Müller (1949) and Moro and Amidei (1953) that the general level of opacification seen clinically is due to calcification at the level of Bowman's layer. Sharply angulated folds, directed towards the stroma, have been described as the basis of a variety of superficial striate corneal opacities and as a sequelae of retinal detachment, trauma, fistula, and atrophy or phthisis of the globe (Schirmer, 1896; Parsons, 1904; Caspar, 1916; Fuchs, 1918; Reis, I921).

Although the mosaic degeneration seen in our case may be regarded at variance with the report of Müller (1949), the dimensions and general morphology of the pattern are similar to those described by other authors. The dimensions are of the same order as those of the normal corneal mosaic (Bron, 1968; Bron and Tripathi, 1969, 1970). This is of particular significance in view of the relationship we have postulated between the anterior corneal mosaic and the anterior mosaic degeneration. It can be shown experimentally and clinically that relaxation of tension in the cornea, such as that produced by buckling the cornea backwards or lowering ocular tension, induces a ridge pattern at the surface of the cornea which corresponds to the anterior corneal mosaic. These ridges are thought to result from the arrangement of collagen bundles near the surface of the cornea (Bron and Tripathi, 1970). The interlacing of collagen fibrils and adjacent lamellae of normal stroma is minimal in many vertebrates 


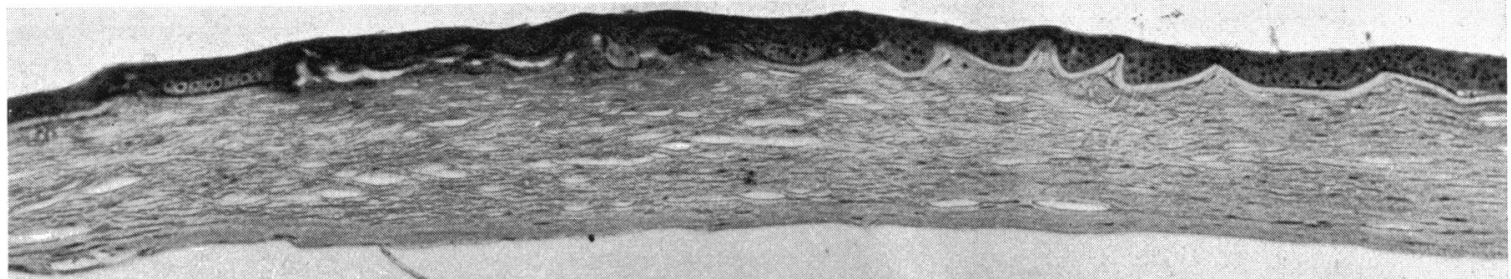

a

FIG. $2 a$ Survey photomicrograph of the cornea in a histological section passing through the region of mosaic degeneration. The corneal stroma is thin, and Bowman's layer thrown into folds, is irregularly encrusted with calcareous deposits. $\quad \times 75$

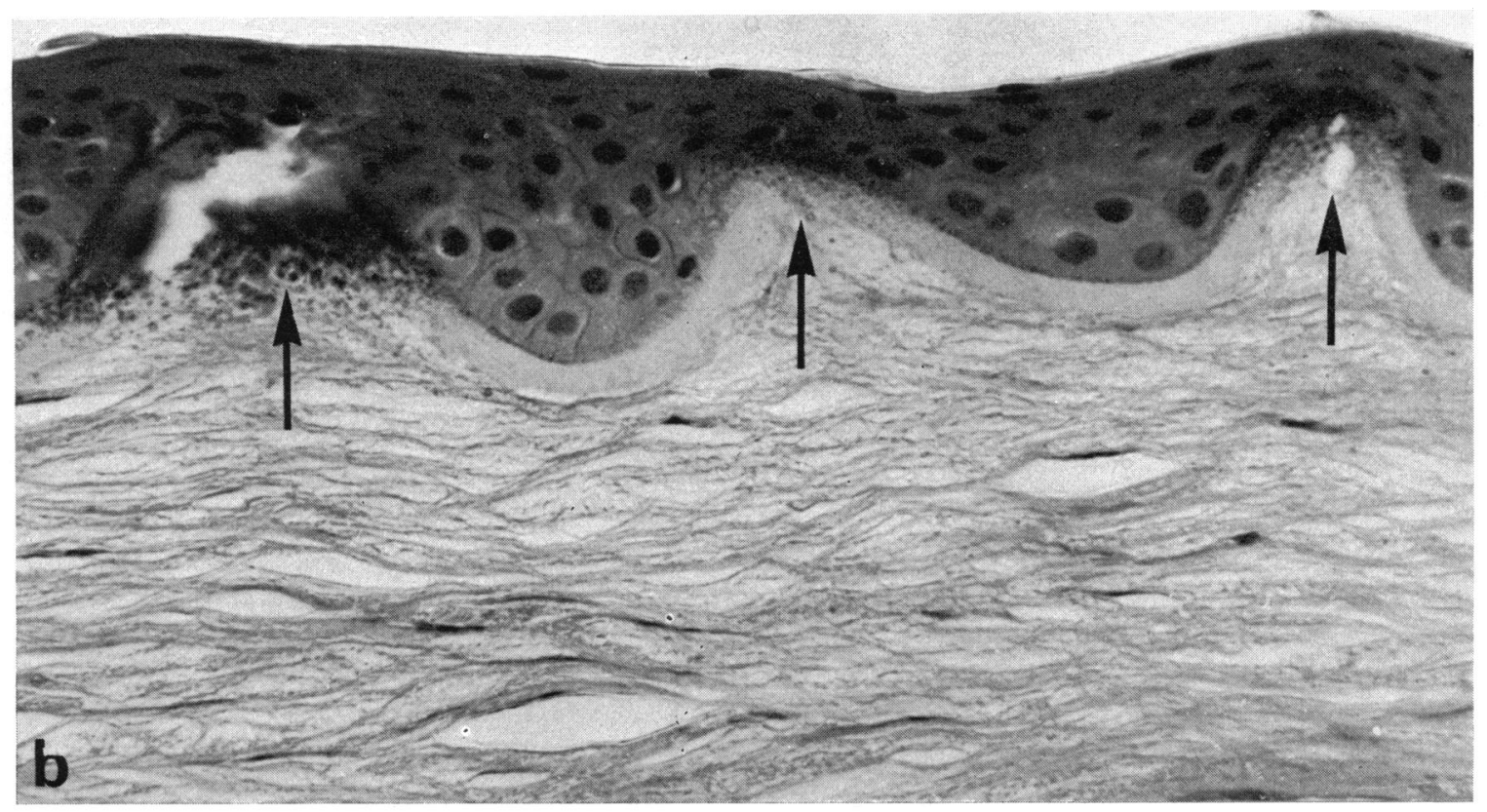

FIG. $2 b$ Higher magnification of anterior cornea, showing pronounced ridges in Bowman's layer (arrows) projecting into the epithelium. The latter has accommodated itself over these undulations and hence there is only minor surface irregularity. The ridges show a variable encrustation with a calcareous granular deposit. $\times 475$

(Virchow, 1910; Payrau, Pouliquen, Faure, and Offret, I967). In man, however, the anterior third of the stroma shows pronounced branching and interweaving of lamellae and many of these are directed towards Bowman's layer from the deeper levels (Tripathi, 1974a) (Fig. 3). At normal intraocular pressure, Bowman's zone is under tension and viewed from the anterior surface appears smooth. By releasing the tension, however, a reproducible polygonal ridged mosaic pattern becomes manifest. The structural basis for this pattern probably lies in the particular arrangement of the prominent collagen lamellae that continue obliquely from the deeper layers of the anterior stroma into Bowman's zone. The terminations of such fascicles expand as they merge into Bowman's layer. It would seem, therefore, that the general statement that individual collagen fibrils within the stromal lamellae pass from limbus to limbus without interruption (Tripathi, 1972, 1974a, b) cannot apply universally in the anterior stroma.

In the posterior stroma, where the lamellae have a more parallel arrangement, such a possibility distinctly exists. In the case described, the white branching mosaic opacity is partly explained by the increased density of the calcium deposits at the apices of the folds in Bowman's layer and partly by the fact that these folds are viewed 'end-on' during biomicroscopy.

A mechanism for the production of the mosaic degeneration in the present case may therefore be proposed as follows. The eye was initially blinded as a result of infection and later became phthisical. 
FIG. 3 Transverse section of normal anterior cornea seen in semipolarized light, showing marked irregularity, variable thickness, and criss-crossing of corneal lamellae. Arrows denote the anterior termination of some lamellae in Bowman's layer, while a progressively horizontal course is taken by the lamellae (asterisk) in the deeper stroma. Adult human eye. Semi-thin Araldite section. $\times 500$

Hypotony resulted in a relaxation of tension at the surface of the cornea so that the ridge pattern was induced permanently. Calcification of Bowman's layer probably followed later, this being not an uncommon secondary event in a phthisical eye.

\section{Summary}

The clinicopathological features and pathogenesis of secondary mosaic degeneration of the cornea (anterior crocodile shagreen of Vogt) are described. The structural basis for the normal anterior corneal mosaic pattern seems to lie in the particular arrangement of many prominent collagen lamellae of the anterior stroma that take an oblique course to gain insertion into Bowman's layer. Since, at normal intraocular pressure, Bowman's layer is under tension, when viewed from the anterior surface the cornea appears smooth. By releasing the tension, however, a reproducible polygonal ridge pattern becomes manifest. It is suggested that a prolonged phthisical state of the eye is one condition wherein the mosaic pattern may become permanent and that, as a secondary event, this is followed by irregular calcification of Bowman's layer which particularly involves the ridges projecting into the epithelium.

Biomicroscopically these ridges corresponded to the branching reticular arrangement of the mosaic opacities.

Our thanks are due to Professor Norman Ashton, F.R.S., for his encouragement, and Miss Augusta de Wit for secretarial assistance.

\section{References}

Boles-CARENinI, B. B. (196I) Brit. F. Ophthal., 45, 64 BRON, A. J. (I968) Ibid., 52, 659 and TRIPATHI, R. C. (I969) Ibid., 53, 760 (1970) Brit. F. physiol. Optics, 25, 8 
Caspar, L. (1916) Klin. Mbl. Augenheilk., 57, 385

COllier, M. (I962) Arch. Ophtal. (Paris), 22, 799

FRANCESCHETTI, A., and ForNI, s. (1950) "Acta XVI Int. Congr. Ophthal. London," vol. I, p. 193. B.M.A.

London

FUCHs, E. (1918) v. Graefes Arch. Ophthal., 96, 3 I 5

KOPŠA, M., and MARUŠIĆ, K. (1958) Ophthalmologica (Basel), 136, 83.

MALbRÁN, E., D'Alessandro, c., and VAlenzuela, J. (1965) Ibid., 149, I6I

MORO, F., and AMIDEI, B. (I953) G. ital. Oftal., 6, 444

MÜLleR, P. (1949) Ann. Oculist. (Paris), 182, 122

PARSons, J. (1904) "Pathology of the Eye", vol. I, p. 182. Hodder and Stoughton, London

PAYraU, P., POUliquen, Y., FAURe, J. P., and offret, G. (1967) "La transparence de la cornée. Les mécanismes de ses altérations". Masson, Paris

REIS, w. (192 I) v. Graefes Arch. Ophthal., 105, 6 I 7

SCHIRMER, O. (1896) Ibid., $\mathbf{4 2}^{2}$ (3), I

TRIPATHI, R. C. (1972) "Ultrastructure of the Normal Cornea", Chap. 3, in "Corneal Grafting", ed. T. A.

Casey, p. 38. Butterworths, London

(1974a) Trans. ophthal. Soc. U.K., 94, 662

(1974b) "Applied Physiology and Anatomy: Tears, Conjunctiva, Cornea and Ocular Adnexa",

Chap. 3 in "Contact Lens Practice", ed. M. Ruben. Baillière, Tindall, London (In press)

VAlerio, м. (1939) Boll. Oculist., 18, 659

(1942) Arch. Ottal., 49, I, 76

virchow, н. (г9ı) "Graefe-Saemisch Handbuch der gesammten Augenheilkunde", 2nd ed., vol. I. Engelmann, Leipzig

voGT, A. (1930) "Lehrbuch und Atlas der Spaltlampenmikroskopie", 2nd. ed., vol. I, p. I I4. Springer, Berlin 